\title{
Comparative study between pre-emptive intramuscular ephedrine and intravenous ephedrine to prevent hypotension during spinal anaesthesia in caesarean section
}

\author{
Arnab Paul ${ }^{1}$, Sonal Khatavkar ${ }^{2}$, Aparajita Nathroy ${ }^{3}$, Hashim Qadri ${ }^{4}$, \\ Jateen Amonkar ${ }^{5}$, \\ ${ }^{1}$ (Senior Resident, Department of Anaesthesia, Dr. D. Y. Patil Medical College, Dr. D. Y. Patil Vidyapeeth \\ [DPU], Pune) \\ ${ }^{2}$ (Professor Department of Anaesthesia, Dr. D. Y. Patil Medical College, Dr. D. Y. Patil Vidyapeeth [DPU], \\ Pune) \\ 3,4,5 (Junior Resident, Department of Anaesthesia, Dr. D. Y. Patil Medical College, Dr. D. Y. Patil Vidyapeeth \\ [DPU], Pune)
}

\begin{abstract}
:
Introduction: There is a considerable dispute over use of different techniques for prevention of hypotension during caesarean section. Spinal Anesthesia induced hypotension in obstetric patients is still a challenge for many anaesthesiologists as it may lead to complications like reduced utero-placental blood flow leading to fetal acidosis.

Aims: The aim of the present study is to compare the effects and side effects of ephedrine administered via two different routes, that is intravenous and intramuscular route.

Methods and materials: Institutional Ethics Committee approval was taken before the commencement of the study. An informed and written consent was taken from every patient selected for the study. A randomized study was done on 60 parturient aged between 20-30years, divided into Group IM (n=30) where intramuscular ephedrine $30 \mathrm{mg}$ given $10 \mathrm{~min}$ prior to spinal anaesthesia and Group IV $(n=30)$ where intravenous ephedrine $12 \mathrm{mg}$ given at the time of spinal anaesthesia. After intravenous preloading $(10-15 \mathrm{ml} / \mathrm{kg})$, spinal anaesthesia was given, baseline maternal heart rate and arterial blood pressure were recorded before induction and every 2 min for first 10 min and thereafter every 5 min for $45 \mathrm{~min}$.

Results: Mean age of patients in group IM and Group IV was $23.03 \pm 2.37$ and $24.47 \pm 2.25$ years respectively $(p>0.05)$. In the intramuscular group, the fall in mean blood pressure after spinal anesthesia was hardly about $10 \%$ of the preoperative blood pressure. In the intravenous group, there was a fall in the blood pressure after spinal anesthesia for a short period of time which was statistically significant $(p<0.05)$.

Conclusion: Prophylactic use of intramuscular ephedrine in parturient prevents hypotension when compared to intravenous ephedrine during caesarean section.
\end{abstract}

Keywords: Ephedrine, Hypotension, Caesarean Section

\section{Introduction}

Spinal anaesthesia induced hypotension during caesarean section is still a challenge for many anesthetists. The incidence of hypotension is more than $80 \%$ without any prophylactic measures. ${ }^{1,2}$ Many complications are associated with intra-operative hypotension like decreased consciousness in parturient, reduced utero-placental blood flow, impaired fetal oxygenation with asphyxial stress and fetal acidosis. ${ }^{3,4}$ The incidence of hypotension can be lowered by several ways like avoidance of aorto-caval compression, preloading with fluids and administration of vasopressor drugs but till date, no single method completely prevents hypotension. ${ }^{4,5}$ Over the last few years, there is a trend to rely more on vasopressors than either crystalloid or colloid alone. ${ }^{6,7}$

There are many vasopressors which are used in spinal induced hypotension like phenylephrine, ephedrine, mephentermine. Ephedrine is the drug of choice as vasopressor agents in obstetric anaesthesia. It is a sympathomimetic amine, acts on part of the sympathetic nervous system (SNS). The principle mechanism of action relies on its indirect stimulation of the adrenergic receptor system by increasing the activity of noradrenaline at the postsynaptic $\alpha$ - and $\beta$-receptors. ${ }^{8}$ It can be administered via both intramuscular and intravenous route. ${ }^{9}$ Intramuscular ephedrine has shown mixed success in preventing spinal induced hypotension. ${ }^{10-12} \mathrm{We}$ have conducted the study to evaluate the role of intramuscular and intravenous ephedrine to prevent spinal induced hypotension in caesarean section. 


\section{Materials and Methods}

Institutional Ethics Committee approval was taken before the commencement of the study. An informed and written consent was taken from every patient selected for the study. The present study was done on 60 female patients with age between 20-35 years, ASA grade I and II, haemodynamically stable, having full term pregnancy posted for elective or emergency caesarean sections under spinal anaesthesia were included in the study. Patients with contraindications for spinal block, coagulopathies, hypersensitivity to local anaesthestic, pregnancy induced hypertension, chronic hypertension, cardiac disease, hyperthyroidism and renal disease were excluded from the study. The patients were randomly divided into two groups of 30 each.

$>$ Group IM - where intramuscular ephedrine $30 \mathrm{mg}$ given 10 minute prior to spinal anaesthesia.

$>$ Group IV- where intravenous ephedrine $12 \mathrm{mg}$ given at time of spinal anaesthesia.

Pre-operative pulse, non invasive blood pressure (NIBP), ECG and oxygen saturation were noted. Peripheral venous access with 20 gauge intravenous cannula was established. Intravenous preloading was done with $15 \mathrm{ml} / \mathrm{kg}$ of Ringer's lactate. Baseline maternal hemodynamic variables were recorded. Spinal anesthesia was administered in the sitting position under all aseptic precautions at L3-L4 interspinous spaces using $26 \mathrm{G}$ quinke's spinal needle. A dose of $2.2 \mathrm{ml}$ of $0.5 \%$ hyperbaric bupivacaine was given. Baseline maternal heart rate, systolic and diastolic blood pressure were noted before induction. After administration of spinal anaesthesia vitals were recorded every 3 minutes for the first 15 minutes and every 5 minutes for the next 45 minutes. Further rescue boluses of ephedrine $6 \mathrm{mg}$ were given if fall in systolic blood pressure was more than $20 \%$ from baseline value. Presence of any complications intraoperatively was noted. Oxygen was administered at a rate of $3 \mathrm{Lmin}^{-1}$ by a face mask to all the patients until the umbilical cord was clamped. Presence of any complications intraoperatively was observed. Apgar score of the new born was also measured.

Statistical Analysis: Statistical analysis was done by using SPSS. t-Test, Chi Square, Repeated ANOVA were applied according to the requirement. The level of significance was fixed at $95 \%$. P value $<0.05$ was considered as statistically significant.

\section{Results}

The demographic data and duration of surgery were similar in each group (Table 1) $(\mathrm{p}>0.05)$. Mean heart rates in both the groups are not statistically significant (Table 2) (p > 0.05). Mean systolic blood pressure at $9^{\text {th }}, 12^{\text {th }}, 15^{\text {th }}$ minutes in Group IM was statistically significant $(\mathrm{p}<0.05)$ (Table 3$)$. Mean diastolic pressure at $12^{\text {th }}$ and $15^{\text {th }}$ minutes in Group IM was statistically significant $(\mathrm{p}<0.05$ ) (Table 4$)$. Mean arterial pressure at $6^{\text {th }}$, $12^{\text {th }}, 15^{\text {th }}$ and $20^{\text {th }}$ minutes in Group IM was also statistically significant $(\mathrm{p}<0.05)$ (Table 5). Apgar score in both the groups were statistically not significant $(\mathrm{p}>0.05)$ (Table 6).

Table 1: Demographic Data in Group IV and Group IM

\begin{tabular}{|c|c|c|c|}
\hline Demographic Data & Group IV & Group IM & P value \\
\hline AGE (Years) & $24.9 \pm 2.32$ & $25.2 \pm 2.71$ & 0.68 \\
\hline WEIGHT (Kg) & $63 \pm 9.52$ & $64.5 \pm 8.71$ & 0.53 \\
\hline GESTATION (Weeks) & $38.3 \pm 0.8$ & $38 \pm 0.9$ & 0.49 \\
\hline
\end{tabular}

$* \mathrm{P}$ Value $<0.05$ statistically significant.

Table 2: Comparison of Mean Heart Rate (HR) in Group IV and Group IM

\begin{tabular}{|c|c|c|c|}
\hline \multirow{2}{*}{ PARAMETERS } & \multicolumn{2}{|c|}{ Mean Heart Rate (BPM) } & \multirow{2}{*}{ P value } \\
\cline { 2 - 4 } & Group IV & Group IM & 0.44 \\
\hline Baseline & 102 & 99 & 0.59 \\
\hline Immediately after induction & 96 & 98 & 0.45 \\
\hline 3 min after induction & 94 & 91 & 0.77 \\
\hline 6 min after induction & 91 & 90 & 0.12 \\
\hline 9 min after induction & 92 & 87 & 0.39 \\
\hline 12 min after induction & 89 & 86 & 0.44 \\
\hline 15 min after induction & 86 & 88 & 0.38 \\
\hline 20 min after induction & 87 & 85 & 0.28 \\
\hline 25 min after induction & 84 & 86 & 0.36 \\
\hline 35 min after induction & 81 & 83 & 0.59 \\
\hline 40 min after induction & 86 & 84 & 0.12 \\
\hline 45 min after induction & 85 & 81 & 0.50 \\
\hline
\end{tabular}

$* \mathrm{P}$ value $<0.05$ is statistically significant. 
Table 3: Comparison of Mean Systolic Blood Pressure (SBP) in group IV and group IM

\begin{tabular}{|c|c|c|c|}
\hline \multirow{2}{*}{ PARAMETERS } & \multicolumn{2}{c|}{$\begin{array}{c}\text { Mean Systolic Blood Pressure } \\
\text { (BPM) }\end{array}$} & \multirow{2}{*}{ P value } \\
\cline { 2 - 4 } & Group IV & Group IM & 0.53 \\
\hline Baseline & $120 \pm 12.3$ & $122 \pm 11.2$ & 0.89 \\
\hline Immediately after induction & $124 \pm 8.2$ & $121 \pm 7.2$ & 0.82 \\
\hline 3 min after induction & $125 \pm 8.8$ & $120 \pm 9.2$ & 0.61 \\
\hline 6 min after induction & $123 \pm 7.8$ & $121 \pm 8.7$ & $0.01^{*}$ \\
\hline 9 min after induction & $116 \pm 8.8$ & $125 \pm 5.2$ & $0.04^{*}$ \\
\hline 12 min after induction & $112 \pm 11.3$ & $122 \pm 8.2$ & $0.00^{*}$ \\
\hline 15 min after induction & $111 \pm 7.45$ & $122 \pm 8.5$ & 0.09 \\
\hline 25 min after induction & $114 \pm 8.1$ & $120 \pm 10.9$ & 0.23 \\
\hline 30 min after induction & $114 \pm 5.8$ & $119 \pm 11.1$ & $0.00^{*}$ \\
\hline 35 min after induction & $110 \pm 10.1$ & $122 \pm 8.5$ & 0.48 \\
\hline 40 min after induction & $116 \pm 8.7$ & $118 \pm 8.9$ & 0.28 \\
\hline 45 min after induction & $115 \pm 11.1$ & $120 \pm 9.8$ & $0.01^{*}$ \\
\hline
\end{tabular}

$* \mathrm{P}$ value $<0.05$ is statistically significant.

Table 4: Comparison of Mean Diastolic Blood Pressure (DBP) in group IV and group IM

\begin{tabular}{|l|l|l|l|}
\hline \multirow{2}{*}{ PARAMETERS } & Mean Diastolic Blood Pressure (BPM) & \multirow{2}{*}{ P value } \\
\cline { 2 - 3 } Baseline & Group IV & Group IM & 0.55 \\
\hline Immediately after induction & $78 \pm 9$ & $80 \pm 8.4$ & 0.79 \\
\hline 3 min after induction & $80 \pm 9.1$ & $81 \pm 7.8$ & 0.33 \\
\hline 6 min after induction & $84 \pm 8.12$ & $80 \pm 7.8$ & 0.7 \\
\hline 9 min after induction & $83 \pm 8.2$ & $82 \pm 8.9$ & 0.69 \\
\hline 12 min after induction & $79 \pm 8.7$ & $81 \pm 9.1$ & $0.01^{*}$ \\
\hline 15 min after induction & $75 \pm 7.2$ & $84 \pm 7.2$ & $0.04 *$ \\
\hline 20 min after induction & $74 \pm 9.3$ & $83 \pm 7.9$ & 0.38 \\
\hline 25 min after induction & $76 \pm 7.2$ & $80 \pm 9.1$ & 0.55 \\
\hline 30 min after induction & $77 \pm 7.5$ & $79.5 \pm 8.6$ & $0.01 *$ \\
\hline 35 min after induction & $73 \pm 7.1$ & $82 \pm 5.74$ & 0.44 \\
\hline 40 min after induction & $76 \pm 10.3$ & $80 \pm 7.5$ & 0.08 \\
\hline 45 min after induction & $75 \pm 7.3$ & $82 \pm 9.3$ & 0.31 \\
\hline
\end{tabular}

$* \mathrm{P}$ value $<0.05$ is statistically significant

Table 5: Comparison of Mean Arterial Pressure (MAP) in group IV and group IM

\begin{tabular}{|c|c|c|c|}
\hline \multirow{2}{*}{ PARAMETERS } & \multicolumn{2}{|c|}{ Mean Arterial Pressure (MAP) } & \multirow{2}{*}{ P value } \\
\cline { 2 - 3 } Baseline & Group IV & Group IM & \\
\hline Immediately after induction & $91 \pm 5.06$ & $92 \pm 5.79$ & 0.55 \\
\hline 3 min after induction & $90 \pm 4.36$ & $91 \pm 4.2$ & 0.57 \\
\hline 6 min after induction & $95 \pm 6.48$ & $92 \pm 6.29$ & 0.34 \\
\hline 9 min after induction & $96 \pm 6.04$ & $91 \pm 5.33$ & $0.05^{*}$ \\
\hline 12 min after induction & $91 \pm 6.1$ & $93 \pm 6.3$ & 0.55 \\
\hline 15 min after induction & $88 \pm 6.17$ & $94 \pm 6.69$ & $0.04^{*}$ \\
\hline 20 min after induction & $89 \pm 5.76$ & $96 \pm 4.93$ & $0.02^{*}$ \\
\hline 25 min after induction & $90 \pm 4.28$ & $93 \pm 3.71$ & $0.01^{*}$ \\
\hline 30 min after induction & $88 \pm 5.17$ & $95 \pm 4.06$ & 0.15 \\
\hline 35 min after induction & $91 \pm 4.76$ & $92 \pm 4.66$ & 0.64 \\
\hline 40 min after induction & $92 \pm 5.5$ & $93 \pm 4.78$ & 0.70 \\
\hline 45 min after induction & $90 \pm 6.24$ & $92 \pm 5.67$ & 0.46 \\
\hline
\end{tabular}

$* \mathrm{P}$ value $<0.05$ is statistically significant.

Table 6: Comparison of Mean Arterial Pressure (MAP) in group IV and group IM

\begin{tabular}{|c|c|c|c|}
\hline Apgar Score & Group IV & Group IM & P value \\
\hline Severely depressed & 4 & 3 & $>0.05$ \\
\hline Moderately depressed & 8 & 6 & $>0.05$ \\
\hline Excellent condition & 18 & 21 & $>0.05$ \\
\hline
\end{tabular}

$* \mathrm{P}$ value $<0.05$ is statistically significant.

\section{Discussion}

The prevention and treatment of maternal hypotension associated with spinal anesthesia for lower segment caesarean section (LSCS) still remains as a challenge to all anesthesiologists. Several pharmacologic 
like vasopressors and non-pharmacologic methods like leg elevation, left uterine displacement and preloading have been used for management of hypotension. No single method has been proved to be superior. Though the ideal prophylactic sympathomimetic drug has not yet been identified, ephedrine is still in use, mostly in Asian countries due to its cost effectiveness. There are very limited studies which had compared efficacy and safety of ephedrine given by two different routes i.e., intravenous and intramuscular. However, intravenous ephedrine is commonly used in many centers to prevent hypotension in LSCS following subarachnoid block. Intravenous single bolus is effective for 5-10 min. So to treat hypotension during intraoperative period, 3-4 boluses are required under spinal anaesthesia in a parturient. On the other hand drugs given by intramuscular route will be available for long time and prevent fall of BP for more than 30-40 min after spinal anaesthesia. ${ }^{13}$

The use of prophylactic ephedrine may be beneficial to prevent maternal hypotension and to potentially avoid fetal late decelerations. Intramuscular prophylactic vasopressors have also been advocated for preventing hypotension associated with spinal anaesthesia for LSCS. ${ }^{14}$ There has been concern about reactive hypertension in previous studies that used intramuscular ephedrine before cesarean delivery, but only a 50-mg dose was associated with hypertension in those studies. ${ }^{15},{ }^{16}$ Though many studies have been performed in order to identify a suitable prophylactic dose of intramuscular ephedrine, a proper dosage regime is yet to be finalized. Because of the nature of ephedrine's effects on the autonomic nervous system, prophylactic ephedrine should be used with caution in patients with cardiovascular disorders. Intramuscular ephedrine was not associated with any maternal and fetal side effect. Prophylactic treatment with $25 \mathrm{mg}$ intramuscular ephedrine did not cause any adverse maternal side effects. ${ }^{17}$

Raskaran et al did a study on 90 patients and reported that in intramuscular ephedrine group $26.66 \%$ patients were observed to have hypotension and only $7 \%$ patients complained about nausea and vomiting and 10 patients required rescue ephedrine. ${ }^{18}$ Varathan et al did a similar study on 49 patients and concluded that $15 \mathrm{mg}$ of intramuscular ephedrine when given $10 \mathrm{~min}$ before, decreased hypotension and provided more hemodynamic stability. ${ }^{13} \mathrm{Webb}$ et al, concluded that a large dose $(37.5 \mathrm{mg})$ of intramuscular ephedrine prevented hypotension without causing reactive hypertension or tachycardia and also provided more sustained cardiovascular support than intravenous ephedrine. In the present study, we demonstrated that $30 \mathrm{mg}$ intramuscular ephedrine given 10 min prior to the subarachnoid block (Group IM) prevented hypotension without causing any fluctuation in the blood pressure. Group IV showed mild decrease in mean diastolic and mean arterial pressure from 10 minutes to 30 minutes after induction $(\mathrm{P}<0.05)$. No reactive hypertension was observed in both the groups. Apgar scores in Group IV and IM did not show much differences $(\mathrm{P}>0.05)$.

Figure 1: Line diagram showing Comparison of Mean HR in Group IV and Group IM

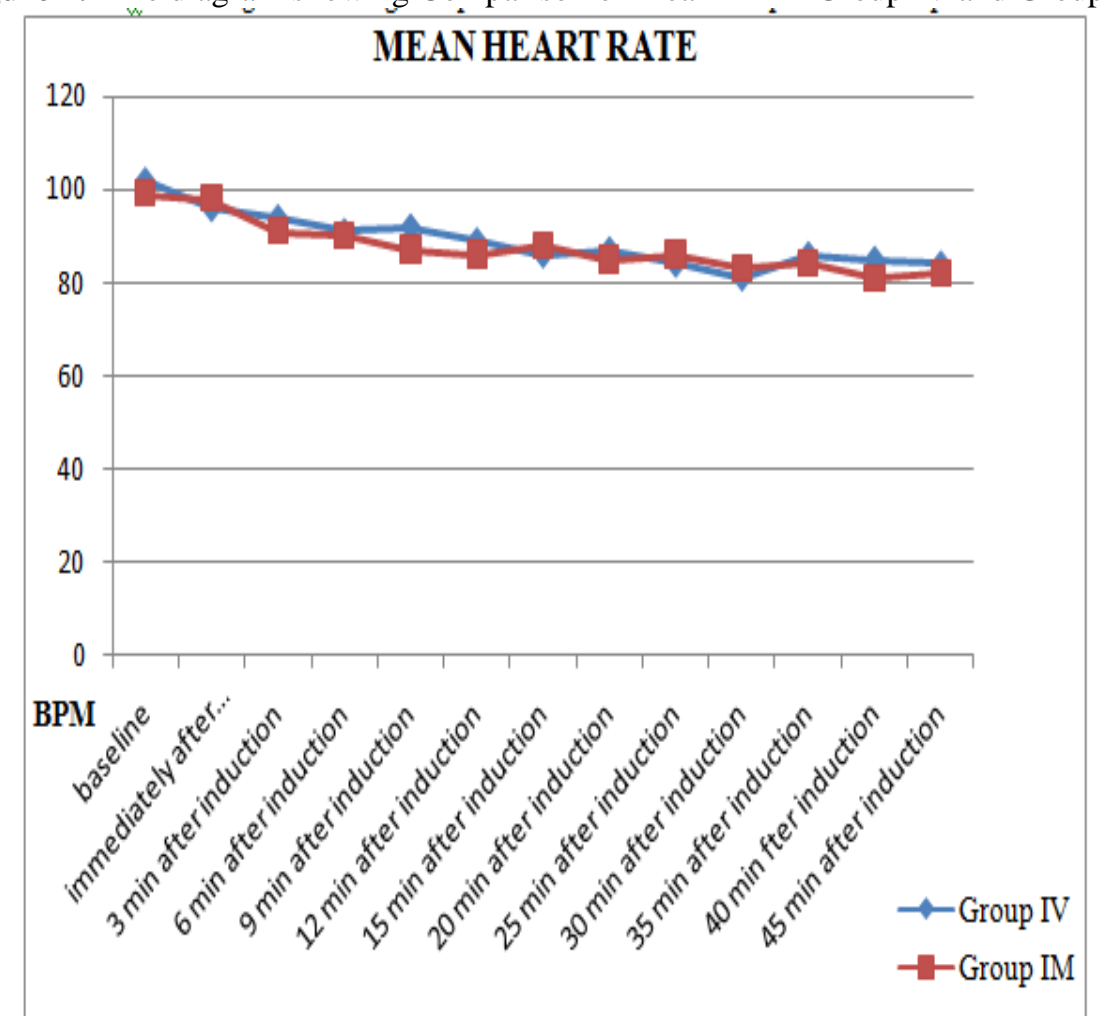

Figure 2: Line diagram showing Comparison of Mean SBP in Group IV and Group IM 


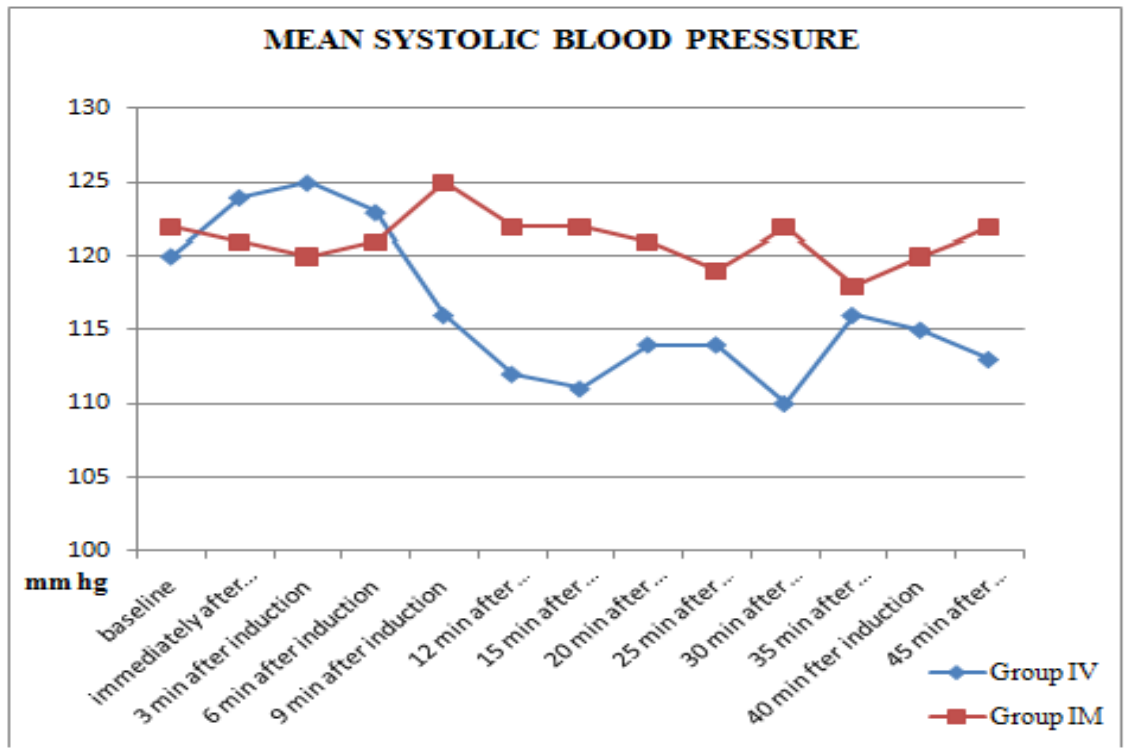

Figure 3: Line diagram showing Comparison of Mean DBP in Group IV and Group IM

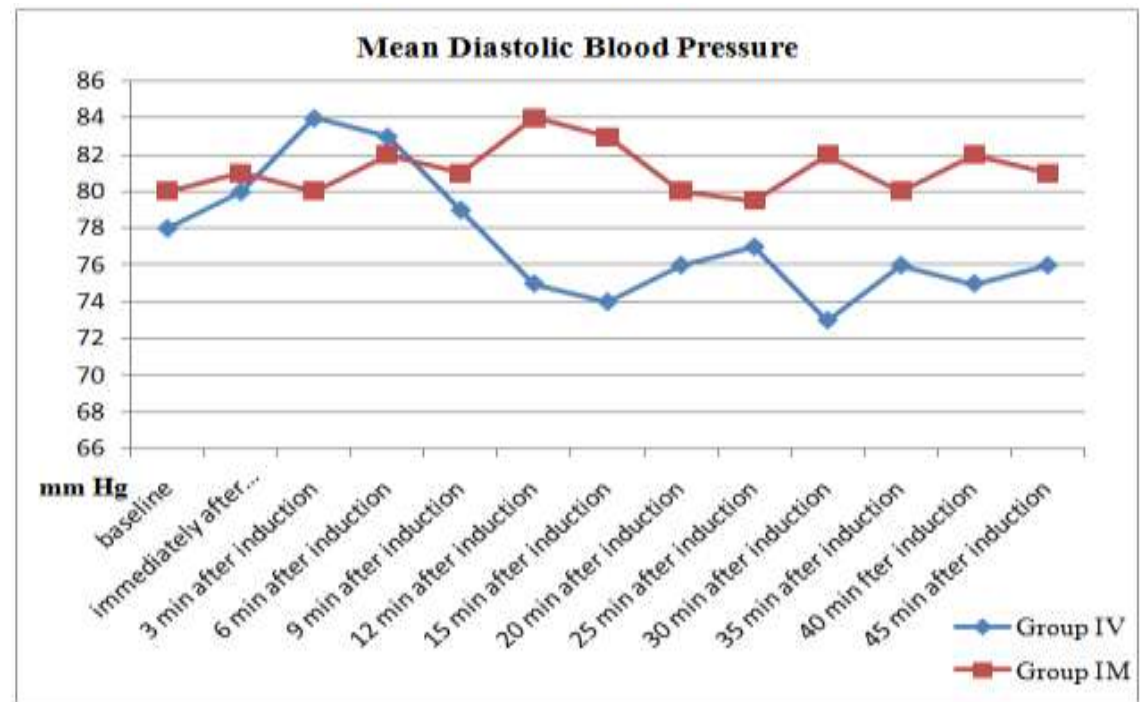

Figure 4: Line diagram showing Comparison of MAP in Group IV and Group IM

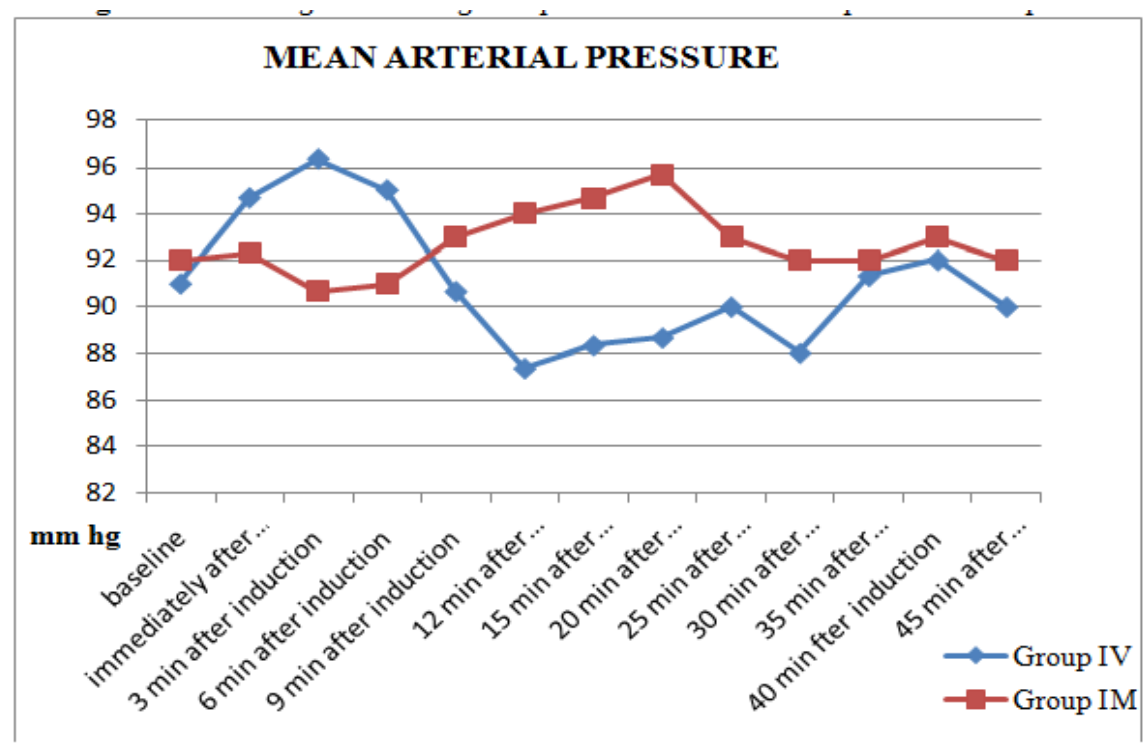




\section{Conclusion}

The study shows that prophylactic administration of intramuscular ephedrine had lower incidence of hypotension as compared to intravenous ephedrine following spinal anaesthesia for caesarean section.

\section{References}

[1]. Saravanan S, Kocarev M, Wilson RC, Watkins E, Columb MO, Lyons G. Equivalent dose of ephedrine and phenylephrine in the prevention of post-spinal hypotension in caesarean section. Br J Anaesth 2006; 96:95-9.

[2]. Stewart A, Fernando R, McDonald S, Hignett R, Jones T, Columb M. The dose-dependent effects of phenylephrine for elective cesarean delivery under spinal anesthesia. AnesthAnalg 2010; 111:1230-7.

[3]. Rout CC, Rocke DA. Prevention of hypotension following spinal anesthesia for cesarean section. IntAnesthesiolClin 1994; 32:11735.

[4]. Lee A, Warwick D, Kee N, Gin T. Trails of ephedrine versus phenylephrine for the management of hypotension during spinal anaesthesiaforcaesarean section. AnaesthAnalg 2002;94:920-6.

[5]. Cyna AM, Andrew M, Emmett RS, Middleton P, Simmons SW. Techniques for preventing hypotension during spinal anaesthesia for caesarean section. Cochrane Database Syst Rev 2006; 4:CD002251.

[6]. NganKee WD, Khaw KS, Ng FF, Lee BB. Prophylactic phenylephrine infusion for preventing hypotension during spinal anesthesia for cesarean delivery. AnesthAnalg 2004; 98:815-21.

[7]. NganKee WD, Khaw KS, Ng FF. Prevention of hypotension during spinal anesthesia for cesarean delivery: An effective technique using combination phenylephrine infusion and crystalloid cohydration. Anesthesiology 2005; 103:744-50.

[8]. Shearer VE, Ramin SM, Wallace DH. Fetal effects of prophylactic ephedrine and maternal hypotension during regional anesthesia for cesarean section. The Journalof Maternal-Fetal Medicine 1999; 5(2):79-84.

[9]. Jackson R, Reid JA, Thorburn J. Volume preloading is not essential to prevent spinal induced hypotension at caesarean section. Br J Anaesth 1995; 75:262-5.

[10]. Ayorinde BT, Buczkowski P, Brown J, Shah J, Buggy DJ. Evaluation of pre-emptive intramuscular phenylephrine and ephedrine for reduction of spinal anaesthesia-induced hypotension during Caesarean section. Br J Anaesth 2001;86:372-6.

[11]. Simon L, Provenchere S, de Saint Blanquat L, Boulay G, Hamza J. Dose of prophylactic intravenous ephedrine during spinal anesthesia for cesarean section. J ClinAnesth 2001;13: 366-9.

[12]. Vercauteren MP, Coppejans HC, Hoffmann VH, Mertens E, Adriaensen HA. Prevention of hypotension by a single 5-mg dose of ephedrine during small-dose spinal anesthesia in prehydrated cesarean delivery patients. AnesthAnalg 2000;90: 324-7.

[13]. Varathan S, Ekanayake SU, Amarasinghe U. Comparison of Prophylactic Intramuscular Ephedrine with Preloading versus Preloading Alone in Prevention of Hypotension During Elective Caesarean Section Under Subarachnoid Block. Sri Lankan Journal of Anaesthesiology 2009; 17: 55-60.

[14]. AbdulH,ShaharbanoS, Khojeste J. Ephedrine for prevention of hypotension comparison between intravenous,intramuscular and oral administration during spinal anaesthesia forelective caesarean section. Professional Med J 2007;14(4): 610-15.

[15]. Rout CC, Rocke DA, Brijball R, Koovarjee RV. Prophylactic intramuscular ephedrine prior to cesarean section. Anaesth Intensive Care 1992;20:448-52.

[16]. Webb AA, Shipton EA. Re-evaluation of IM ephedrine as prophylaxis against hypotension associated with spinal anaesthesia for Caesarean section. Can J Anaesth 1998;45:367-9.

[17]. Cleary-Goldman. Prophylactic Ephedrine and Combined Spinal Epidural: Maternal Blood Pressure and Fetal Heart Rate Pattern. The American College of Obstetricians and Gynecologists. 2005; 106 (3):466-72.

[18]. Raskaran S, Nema N, Mujalde M, Mrinal K, Verma J, Mantri N, et al. A Comparison of Pre-Emptive Intramuscular Phenylephrine and Ephedrine in Prevention of Spinal Anesthesia Induced Hypotension during Caesarean Section. Journal of Evolution of Medical and Dental Sciences 2014;3:13835-44. 